\title{
Localization of poly(A) Sequences that are Lost during Oocyte Maturation of Xenopus laevis
}

\author{
Keiji Okuyama, Noriyuki Sagata*, Koichiro Shiokawa and Kiyotaka \\ Yamana \\ Department of Biology, Faculty of Science, Kyushu University 33, Fukuoka, \\ 812 Japan
}

\begin{abstract}
Xenopus oocytes and eggs were fractionated into post-mitochondrial supernatant and pellet fractions, after which the content of poly(A) sequences and their size distribution were analyzed. It was found that, while the poly(A) content in the post-mitochondrial supernatant fraction remained constant during oocyte maturation, that in the pellet fraction decreased significantly without any change in its sequence length. This decrease in poly(A) content as has recently been reported to occur during oocyte maturation can thus be confined to the pellet fraction.
\end{abstract}

Recently, Darnbrough and Ford (3) and Sagata et al. $(6,7)$ have demonstrated independently that the poly(A) content of RNA is greatly reduced during oocyte maturation of Xenopus laevis, and that this probably gives rise to depolyadenylated RNA. Recently, the present authors have suggested that depolyadenylated maternal mRNA is again polyadenylated in the cytoplasm soon after fertilization (7). It seems therefore that such polyadenylation and depolyadenylation are important for the utilization of maternal mRNA during oocyte maturation and during the early development of amphibians.

In the present experiment, Xenopus oocytes and eggs were fractionated into postmitochondrial supernatant (PMS) and pellet (P) fractions by low-speed centrifugation. The contents of poly(A) were measured and its size distribution analyzed. The decrease in poly(A) content that was observed, took place soley in the $\mathrm{P}$ fraction and did not involve any change in size. Furthermore, there is the interesting possibility that this decrease in content is accompanied by the intracellular transport of poly(A), and this transport is possibly coupled with mRNA mobilization.

Full-grown Xenopus oocytes, and mature eggs 6-10 h after germinal vesicle breakdown were used (6), after having keen defolliculated or dejellied. Maturation was induced by progesterone $(10 \mu \mathrm{g} / \mathrm{ml})$. Germinal vesicles were removed manually (4). DOC was added immediately before homogenization. The homogenate was centrifuged at $12,000 \mathrm{~g}$ for $10 \mathrm{~min}$ to fractionate into P and PMS. Ribosomes, polysomes and other particulate materials were precipitated by adding ethanol to the PMS fraction. The $\mathrm{P}$ and the precipitate from PMS were homogenized in Tris- $\mathrm{HCl}(\mathrm{pH}$

* Present address: Department of Viral Oncology, Cancer Institute, Kami-Ikebukuro, Toshima-ku, Tokyo, 170 Japan

Abbreviations used: PMS, post-mitochondrial supernatant; P, pellet; DOC, sodium deoxycholate: SDS, sodium dodecyl sulfate. 
9.0)- $0.5 \%$ SDS- $10 \mu \mathrm{g} / \mathrm{ml}$ polyvinyl sulfate, and mixed with phenol. Poly(A) sequences were prepared by digesting the obtained RNA with RNase $A$ and $T_{1}$, and electrophoresed on an SDS- $10 \%$ polyacrylamide gel. The sequences were eluted from gel slices and measured by hybridization with $\left[{ }^{3} \mathrm{H}\right]$ poly $(\mathrm{U})(1.36 \mathrm{mCi} / \mathrm{mg})$. Procedures have been described elsewhere $(7,8)$.

Table 1 shows the contents of total RNA and poly(A) in the P and PMS fractions of oocytes and eggs. Total RNA content remains fairly constant and its subcellular distribution does not change during oocyte maturation and ovulation. The PMS of oocytes and eggs contains about $90 \%$ of the total RNA, and nearly all of it is ribosomal. The rest is contained in the $\mathrm{P}$, and at least a part of it is due to contaminating cytoplasmic components (7). This agrees with the results of previous research $(1,11)$.

The contents and distribution of poly(A), however, change markedly during oocyte maturation (Table 1). The oocytes contain $1.8 \mathrm{ng}$, while the PMS and P each contain half of the total cellular poly(A). Poly(A) content decreases to $1.1 \mathrm{ng}$ in the eggs, and here, the PMS contains $87 \%$ of the total. The result is that the amount of poly(A) in the PMS does not differ between oocytes and eggs. On the other hand, the P fraction loses the majority of its sequences while the oocyte is converting into an egg. It has already been demonstrated that almost all of the poly(A) in Xenopus oocytes and eggs is associated with RNA moieties (7); therefore, poly(A) is synonymous with poly(A) ${ }^{+}$RNA.

Fig. 1 shows the size distribution of poly(A) sequences. Size here was found to be very heterogeneous, as reported earlier for whole oocytes and eggs $(3,6)$. There is no significant difference between the P and PMS fractions of either oocytes or eggs. The sequences are 20 to 100 nucleotides long, and seem to be slightly longer in eggs than in oocytes. This suggests that the observed decrease in content is not due to a shortening in sequence length; rather that it is the number of poly(A) sequences which decreases. As further evidence, previous studies of whole oocytes and eggs have revealed that the poly(A) sequences in eggs were $60 \%$ of the number in oocytes $(3,6)$.

The pellet fraction contains a variety of cytoplasmic components such as mitochondria, yolk platelets and pigments, as well as nuclei and cell debris, that would sediment under the present conditions. However, as far as poly(A) is concerned, the nuclei and mitochondria do not seem to contribute significantly. The poly(A) content of each is

TABLE 1. SubCELlULAR DiSTRIBUTIONS OF TOTAL RNA AND POLY(A) IN THE OOCYTE AND THE EGG ${ }^{\text {a }}$

\begin{tabular}{|c|c|c|c|c|c|c|c|c|}
\hline \multirow{2}{*}{ Stages } & \multicolumn{3}{|c|}{ 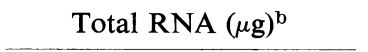 } & \multicolumn{5}{|c|}{$\operatorname{Poly}(\mathrm{A})(\mathrm{ng})^{\mathrm{c}}$} \\
\hline & PMS & $\mathrm{P}$ & Whole & PMS & $P$ & Nucleus & $\begin{array}{l}\text { Mitochon- } \\
\text { dria }\end{array}$ & Whole \\
\hline Full-grown oocyte & $\begin{array}{c}4.96 \\
(91.1 \%)\end{array}$ & $\begin{array}{c}0.49 \\
(8.9 \%)\end{array}$ & $\begin{array}{c}5.45 \\
(100 \%)\end{array}$ & $\begin{array}{c}0.847 \\
(48.1 \%)\end{array}$ & $\begin{array}{c}0.913 \\
(51.9 \%)\end{array}$ & $\begin{array}{r}0.104^{\mathrm{d}} \\
(5.9 \%)\end{array}$ & $(<6 \%)^{\mathrm{e}}$ & $\begin{array}{c}1.76 \\
(100 \%)\end{array}$ \\
\hline Mature egg & $\begin{array}{c}4.95 \\
(90.9 \%)\end{array}$ & $\begin{array}{c}0.50 \\
(9.1 \%)\end{array}$ & $\begin{array}{c}5.45 \\
(100 \%)\end{array}$ & $\begin{array}{c}0.938 \\
(86.7 \%)\end{array}$ & $\begin{array}{c}0.144 \\
(13.3 \%)\end{array}$ & - & - & $\begin{array}{c}1.08 \\
(100 \%)\end{array}$ \\
\hline
\end{tabular}

a Oocytes and eggs were homogenized and fractionated into post-mitochondrial supernatant (PMS) and pellet $(\mathrm{P})$ fractions. The values shown are the means of three independent determinations.

b Calculated from the optical density $\left(1 \mathrm{mg}=22 \mathrm{OD}_{260}\right)$.

c Calculated from the hybridization with ${ }^{3} \mathrm{H}$-poly(U).

d Determined on germinal vesicles isolated by the enucleation method of Ford and Gurdon (4).

e Taken from Cabada et al. (2). 


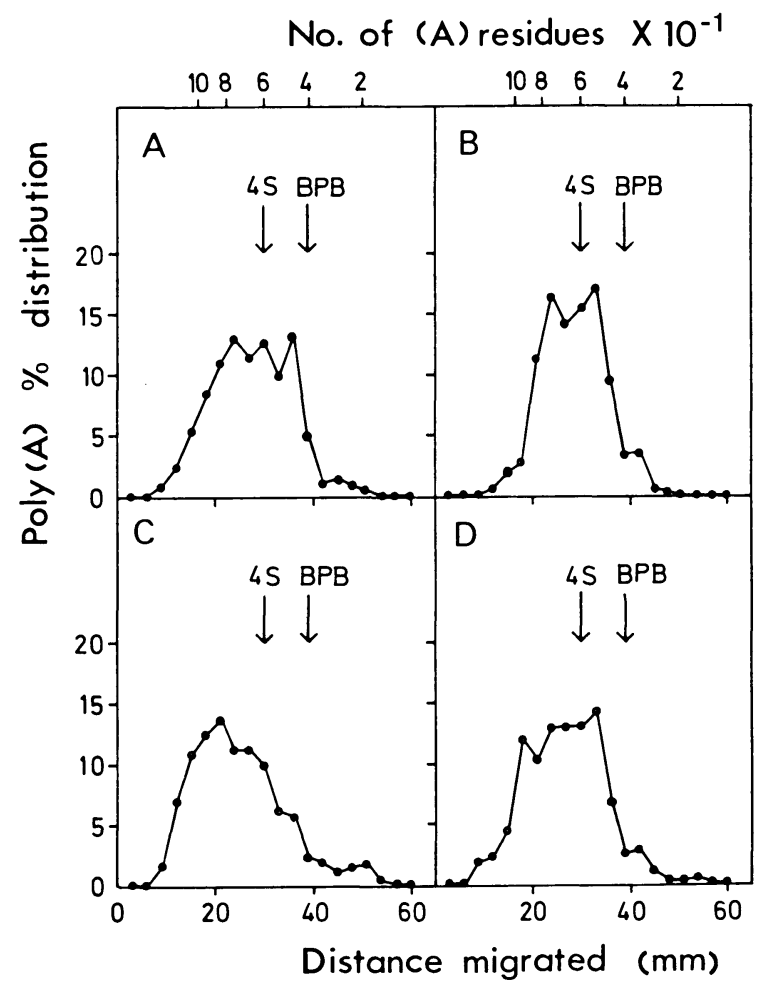

Fig. 1. Polyacrylamide gel electrophoretic patterns of poly(A) sequences from post-mitochon drial supernatant (PMS) and pellet (P) fractions. Oocytes and eggs were homogenized and fractionated into PMS and P. RNA was prepared with phenol, and poly(A) sequences obtained were electrophoresed on an SDS-polyacrylamide gel. After being eluted from gel slices, the poly(A) sequences were hybridized with $\left[{ }^{3} \mathrm{H}\right]$ poly $(\mathrm{U})$ and then counted. The results are expressed for each slice as the percentage of total poly(U) binding per gel. Approximate poly(A) size calibration is shown at the top of the figure. Positions of E. coli 4S transfer RNA (as the internal marker) and the dye (bromophenol blue) are indicated .(A) oocyte PMS; (B) oocyte P; (C) egg PMS; (D) egg P.

only $5-6 \%$ of the total (Table 1 ). The poly(A) sequences or poly (A) ${ }^{+}$RNA that disappears from the $\mathrm{P}$ of maturing oocytes may not be bound to membraneous structures such as the endoplasmic reticulum, judging from the fact that most poly(A) sequences were not solubilized by DOC. Actually, there is little endoplasmic reticulum in amphibians during early developmental stages $(9,10)$. The poly(A) sequences are likely to be associated with some "rapidly sedimenting structures", which, it is claimed in another system, are involved in the nuclear-cytoplasmic transfer of mRNA (5). The fate of the poly(A)+RNA supposedly released from the $\mathrm{P}$ is not known at present. In this connection, the authors have observed that early in maturation, there is a transient increase in poly(A) content in the PMS, the extent of which corresponds roughly to that of the decrease observed in the $\mathrm{P}$ (unpublished). This may suggest that there is a transfer or mobilization of poly(A) sequences from the P to the PMS fraction during oocyte maturation. These results may help clarify the processes of poly $(\mathrm{A})^{+}$ RNA mobilization and utilization during oocyte maturation and early embryonic development. 
Acknowledgment. This work was supported in part by a Grant-in-Aid for Scientific Research from the Ministry of Education, Science and Culture, Japan.

\section{REFERENCES}

1. Brown, D.D. and E. LittNa. RNA synthesis during the development of Xenopus laevis, the African clawed toad. J. Mol. Biol. 8, 669-687, 1964

2. Cabada, M.O., C. Darnbrough, P.J. Ford and P.C. Turner. Differential accumulation of two size classes of poly(A) associated with messenger RNA during oogenesis in Xenopus laevis. Develop. Biol. 57, 427-439, 1977

3. DarnBrough, C. and P.J. Ford. Turnover and processing of poly(A) in full-grown oocytes and during progesterone-induced oocyte maturation in Xenopus laevis. Develop. Biol. 71, 323340,1979

4. Ford, C.C. and J.B. Gurdon. A method for enucleating oocytes of Xenopus laevis. J. Embryol. exp. Morphol. 37, 203-209, 1977

5. Pogo, A.O., I. Faiferman, K. Shiokawa and L. Branes. in Biochemistry of the Cell Nucleus, Mechanism and Regulation of Gene Expression (ed. Hidvégi E.J., J. Sümegi and P. Venetianer), North-Holland/American Elsevier, New York, 1975

6. Sagata, N., K. Shiokawa and K. Yamana. Metabolism of poly(A) sequences of maternal mRNA during progesterone-induced maturation of Xenopus laevis oocytes. Cell Struc. Func. 5, 67-79, 1980

7. Sagata, N., K. Shiokawa and K. Yamana. A study on the steady-state population of poly(A)+ RNA during early development of Xenopus laevis. Develop. Biol. 77, 431-448, 1980

8. Sagata, N., K. Shiokawa and K. Yamana. Appearance of RNA with a specific size class of poly(A) in oocytes and eggs in HCG-stimulated Xenopus laevis females. J. exp. Zool. 213, 117122,1980

9. Van GANSEN, P. Étude au microscope électronique des structures ribosomales du cytoplasme au cours de la segmentation de l'oeuf de Xenopus laevis. Exp. Cell Res. 47, 157-166, 1967

10. Wischnitzer, S. The ultrastructure of the cytoplasm of the developing amphibian eggs. in Advances in Morphogenesis, Vol. 5, ed. Abercrombie M and J. Brachet, Academic Press, New York and London, pp. 131-179, 1966

11. Woodland, H.R. Changes in the polysome content of developing Xenopus laevis embryos. Develop. Biol. 40, 90-101, 1974 